\title{
Direct measurement of the spectral transfer function of a laser based anemometer
}

\author{
Angelou, Nikolas; Mann, Jakob; Sjöholm, Mikael; Courtney, Michael
}

Published in:

Review of Scientific Instruments

Link to article, DOI:

$10.1063 / 1.3697728$

Publication date:

2012

Document Version

Publisher's PDF, also known as Version of record

Link back to DTU Orbit

Citation (APA):

Angelou, N., Mann, J., Sjöholm, M., \& Courtney, M. (2012). Direct measurement of the spectral transfer function of a laser based anemometer. Review of Scientific Instruments, 83(3), 033111.

https://doi.org/10.1063/1.3697728

\section{General rights}

Copyright and moral rights for the publications made accessible in the public portal are retained by the authors and/or other copyright owners and it is a condition of accessing publications that users recognise and abide by the legal requirements associated with these rights.

- Users may download and print one copy of any publication from the public portal for the purpose of private study or research.

- You may not further distribute the material or use it for any profit-making activity or commercial gain

- You may freely distribute the URL identifying the publication in the public portal

If you believe that this document breaches copyright please contact us providing details, and we will remove access to the work immediately and investigate your claim. 


\section{AIP}

\section{Direct measurement of the spectral transfer function of a laser based anemometer}

Nikolas Angelou, Jakob Mann, Mikael Sjöholm, and Michael Courtney

Citation: Rev. Sci. Instrum. 83, 033111 (2012); doi: 10.1063/1.3697728

View online: http://dx.doi.org/10.1063/1.3697728

View Table of Contents: http://rsi.aip.org/resource/1/RSINAK/v83/i3

Published by the American Institute of Physics.

\section{Related Articles}

Turbulence measurements in a rotating magnetic field driven flow

Phys. Fluids 24, 045105 (2012)

Multi-chord fiber-coupled interferometer with a long coherence length laser

Rev. Sci. Instrum. 83, 033506 (2012)

Note: A method to isolate and detect a large number of single molecules by microdroplet fluorescence spectroscopy

Rev. Sci. Instrum. 83, 036107 (2012)

A new quasi-steady method to measure gas permeability of weakly permeable porous media

Rev. Sci. Instrum. 83, 015113 (2012)

Rheological measurements of large particles in high shear rate flows

Phys. Fluids 24, 013302 (2012)

\section{Additional information on Rev. Sci. Instrum.}

Journal Homepage: http://rsi.aip.org

Journal Information: http://rsi.aip.org/about/about_the_journal

Top downloads: http://rsi.aip.org/features/most_downloaded

Information for Authors: http://rsi.aip.org/authors

\section{ADVERTISEMENT}

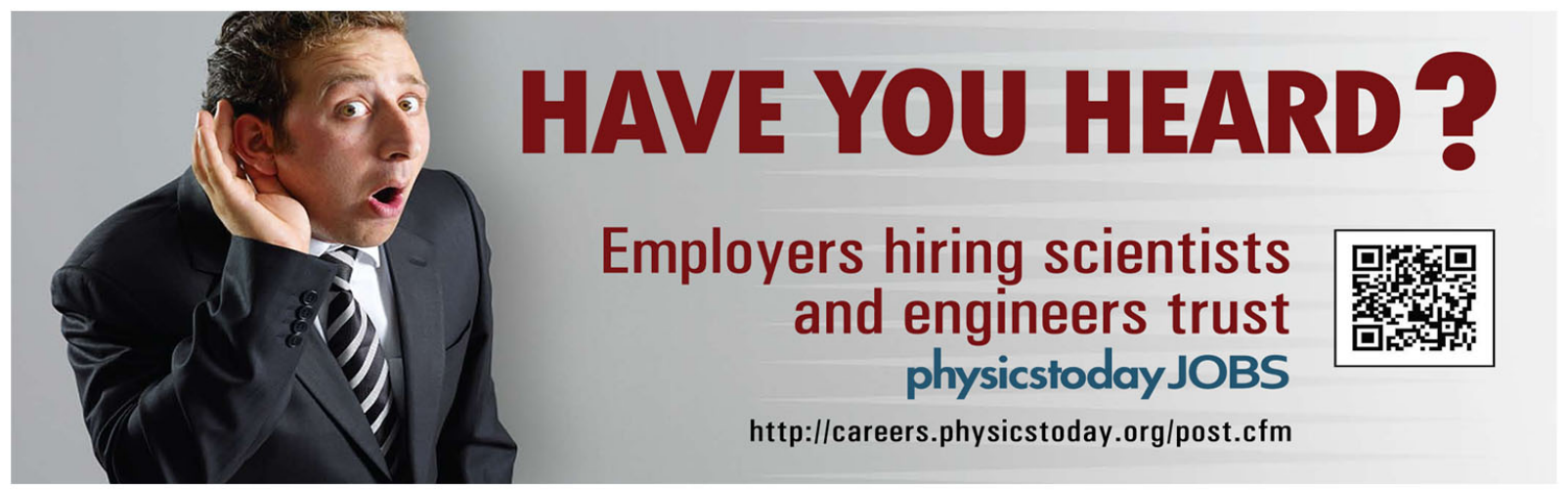




\title{
Direct measurement of the spectral transfer function of a laser based anemometer
}

\author{
Nikolas Angelou, Jakob Mann, Mikael Sjöholm, and Michael Courtney \\ Department of Wind Energy, Danish Technical University, Frederiksborgvej 399, Roskilde 4000, Denmark
}

(Received 19 July 2011; accepted 4 March 2012; published online 27 March 2012)

\begin{abstract}
The effect of a continuous-wave (cw) laser based anemometer's probe volume on the measurement of wind turbulence is studied in this paper. Wind speed time series acquired by both a remote sensing $\mathrm{cw}$ laser anemometer, whose line-of-sight was aligned with the wind direction, and by a reference sensor (sonic anemometer) located in the same direction, were used. The spectral transfer function, which describes the attenuation of the power spectral density of the wind speed turbulence, was calculated and found to be in good agreement with the theoretical exponential function, which is based on the properties of the probe volume of a focused Gaussian laser beam. Parameters such as fluctuations of the wind direction, as well as the overestimation of the laser Doppler spectrum threshold, were found to affect the calculation of the spectral transfer function by introducing high frequency noise. ( $) 2012$ American Institute of Physics. [http://dx.doi.org/10.1063/1.3697728]
\end{abstract}

\section{INTRODUCTION}

A continuous-wave (cw) laser based anemometer uses the Doppler shift of the backscattered light from atmospheric aerosols and molecules to remotely sense the wind speed and direction. ${ }^{1}$ The backscattered light is collected from an air volume with a relatively large size in respect to turbulence length scales, thus it is vital to determine the extent of associated attenuation of the turbulent speed fluctuations. This is crucial for the use of such a sensor in research related with scientific areas like wind energy, where the advantages of remote sensing (i.e., cw laser anemometers or pulsed wind lidars) could prove beneficial for their further development. ${ }^{2}$

The objective of this study is to estimate the power spectral density attenuation of the wind speed turbulence, measured by a laser anemometer, through the calculation of the spectral transfer function. The assessment of this function is preferably done in a geometry where the turbulent fluctuations of the wind speed are probed from a horizontal plane parallel to the wind flow, in which both the effect of the vertical component of the wind speed, which is expected to introduce an error in the estimation of the turbulence attenuation, as well as the effect of height dependent wind speed variations, due to the wind shear, are minimized.

\section{EXPERIMENTAL SETUP}

Such ideal opportunities for assessing the spatial filtering function were obtained during a 3 month (April-June 2009) measurement campaign in the context of the European research project UPWIND, where a ZephIR prototype was mounted on the nacelle of a Vestas V27 wind turbine $(225 \mathrm{~kW}$ model, with a hub height of $33.5 \mathrm{~m}$ and a rotor diameter of $27 \mathrm{~m}$ ) in the vicinity of a meteorological mast (met mast) equipped with a reference sensor (Metek USA1 sonic anemometer) at Ris $\varnothing$ DTU in Denmark $\left(55^{\circ} 41^{\prime} 08^{\prime \prime}\right.$ $\left.\mathrm{N}, 12^{\circ} 05^{\prime} 46^{\prime \prime} \mathrm{E}\right)$. The measurements used in this study are from the rare periods of the campaign when the wind direc- tion coincided with the line-of-sight of the ZephIR while it was pointing towards the reference sensor.

The ZephIR prototype is a cw laser anemometer capable of acquiring measurements of the line-of-sight wind speed at different distances away from the instrument. It was manufactured by QinetiQ (UK) in 2003, as a prototype of the nowadays commercially available ZephIR laser anemometer produced by Natural Power (UK). Its design concept follows the fundamental principles of a monostatic, fiber-based, coherent detection cw laser anemometer. ${ }^{3}$ The theoretical spatial and temporal resolution of this system have been thoroughly studied $^{4,5}$ and its ability to accurately measure the wind speed has been verified through inter-comparison with data acquired by calibrated cup anemometers. ${ }^{6}$ The design of the system offers the possibility of operating in two different modes; a staring mode (laser beam is emitted in a straight line parallel with the orientation of the system) and a conical scanning mode (the laser beam is deflected by a rotating optical wedge prism).

In this application the ZephIR was operating in the staring mode and its line-of-sight was aligned with the horizontal axis of the wind turbine, so that cloud returns were not expected to interfere with the detected backscattered signals. ${ }^{7}$ The focus distance of the laser beam was set to $67.5 \mathrm{~m}$, which is approximately equal with the horizontal distance between the V27 wind turbine and the met mast. Prior to the installation on the nacelle, the ZephIR prototype was focus calibrated using a solid moving target in order to ensure high precision and accuracy in the determination of the focus distance.

The ZephIR prototype's data acquisition unit had a sampling rate of $50 \mathrm{MHz}$ and a Discrete Fourier Transform (DFT) was applied in sequences of 512 consecutive measurements in order to create one laser Doppler spectrum of wind speeds up to $\sim 19 \mathrm{~ms}^{-1}$, with a spectral resolution of $0.0976 \mathrm{MHz}$ corresponding to $0.076 \mathrm{~ms}^{-1}$. Each spectrum was post-processed in order to filter away the background noise and subsequently a velocity estimation was applied, based on the location of the median value of the Doppler spectrum. The system's duty 
cycle was $94.5 \%$, due to the occurrence of a 10-min pause for the calculation of the background signal every $3 \mathrm{~h}$.

A met mast was placed in the direction of $283^{\circ}$ from the North, at a distance of approximately $67.5 \mathrm{~m}$ (equivalent to 2.5 rotor diameters) from the V27 wind turbine. At a height of $32 \mathrm{~m}$ a Metek USA-1 sonic anemometer, measuring with a sampling frequency of $32 \mathrm{~Hz}$, was used as a reference instrument for the inter-comparison with the ZephIR laser anemometer. The selection of a sonic anemometer was based on the need to acquire all the 3 components of the wind speed. The location of the focus of the laser beam was estimated to be approximately $1 \mathrm{~m}$ above the USA-1 sonic anemometer.

The data acquisition of the two instruments was synchronized using a network time server and the synchronization was verified through a cross correlation study between the time series of the wind speed measurements. Therefore it can be considered that the two instruments were acquiring simultaneous measurements of the wind speed, approximately at the same location.

\section{SPATIAL WEIGHTING FUNCTION}

The operation of a laser anemometer is based on focusing a Gaussian laser beam in the atmosphere, thus achieving a sufficiently high signal-to-noise ratio (SNR) of the backscattered radiation. Due to the energy distribution around the focus point the laser anemometer's measurements are characterized by a probe volume, whose length is considered to be equal to twice the Rayleigh length $\left(z_{R}\right){ }^{8}$ The Rayleigh length is defined as the distance between the focus point, where the beam radius has its minimum value (defined as the beam waist), to the point where the area of the beam's cross section becomes twice the beam minimum area and is equal to

$$
z_{R}=\frac{\lambda}{\pi} \frac{r^{2}}{\alpha_{0}^{2}}
$$

where $\lambda$ is the wavelength of the emitted radiation, $r$ the distance between the tranceiver of the remote sensing laser anemometer and the point where the laser beam is focused (focus distance) and $\alpha_{o}$ is the effective radius of the telescope used for emitting and receiving the laser signal. The latter is defined as the radius where the intensity of the Gaussian laser beam has dropped to $e^{-2}$ of its maximum value (in the case of the ZephIR prototype: $\lambda=1547.615 \mathrm{~nm}$ and $\alpha_{0}=20 \mathrm{~mm}$ ). The effect of the probe volume on the SNR has been studied in detail by Refs. 9-11. In particular, if a homogeneous aerosol distribution is assumed, then the radial wind speed $\left(v_{r}\right)$ can be expressed as the convolution of the speed along the lineof-sight and the spatial weighting function $\varphi$ which describes the distribution of the signal intensity received: ${ }^{11}$

$$
v_{r}(r)=\int_{-\infty}^{\infty} \varphi(s) \mathbf{n} \cdot \mathbf{u}((s+r) \mathbf{n}) \mathrm{d} s,
$$

where $\mathbf{n}$ is a unity vector in the line-of-sight of the laser anemometer, $r$ is the focus distance, $s$ is the distance along the line-of-sight from $r, \mathbf{u}$ is the wind field, and $\varphi(s)$ is the spatial weighting function, which is equal to ${ }^{11}$

$$
\varphi(s)=\frac{1}{\pi k \alpha_{0}^{2}} \frac{1}{(s / r)^{2}+(r-s)^{2} /\left(k \alpha_{0}^{2}\right)^{2}},
$$

where $k=2 \pi / \lambda$ is the wavenumber of the laser light. When $r \ll k \alpha_{0}^{2}$ the spatial weighting function can be approximated by a Lorentzian function, equal to

$$
\varphi(s)=\frac{1}{\pi} \frac{z_{R}}{z_{R}^{2}+s^{2}} .
$$

This expression of the spatial filtering has previously been successfully used in order to investigate the spectral attenuation of the turbulence measured by a laser anemometer. $^{12}$

\section{WIND SPEED TIME SERIES IN THE LINE-OF-SIGHT OF THE LASER ANEMOMETER}

For the needs of this study it was necessary to acquire radial wind speed measurements looking upwind towards the met mast, while the wind direction coincided with the line-ofsight of the laser anemometer. The data presented in this paper were acquired when the wind turbine was yawed and its orientation was locked in the direction of $283^{\circ}$, which is the direction of the met mast from the V27 wind turbine (12:00-20:00 on the 05-05-2009). Throughout this period the wind turbine was not operating and the laser beam was completely free of the blades, thus achieving maximum data availability. For the wind directions of the period of investigation, both the mast and the wind turbine were not affected by wakes produced by the adjacent wind turbines in the area. ${ }^{13}$ Moreover, the sonic anemometer was also undisturbed by the wake of the mast.

In order to compare the spectral characteristics of the turbulence measurements from the two instruments, the wind speed measurements from the USA-1 Metek sonic anemometer were first corrected in order to take into account the internal flow distortion caused by the probe geometry. ${ }^{14,15}$ The corrected sonic anemometer velocity components were then projected onto the line-of-sight (n) of the laser anemometer.

In the lower plot of Fig. 1 the time series $(0.1 \mathrm{~Hz})$ of the wind speed as measured by the sonic anemometer and the laser anemometer are presented, while in the upper plot the time series of the wind direction as measured from a wind vane, along with the line-of-sight of the laser anemometer (orange line) are shown. The two 10-min periods (highlighted in gray) when the laser anemometer was not acquiring wind speed data, are due to the measurement of the background signal.

The wind speed data, sampled at $50 \mathrm{~Hz}$ by the laser anemometer $\left(v_{r}\right)$ and at $32 \mathrm{~Hz}$ by the sonic anemometer $(v)$, were block averaged to create $10 \mathrm{~Hz}$ time series and four 1-h periods, characterized by different mean wind directions (denoted as A, B, C, and D), were selected to be investigated. The downsampling of the sonic anemometer time series from $32 \mathrm{~Hz}(v)$ to $10 \mathrm{~Hz}\left(v_{s}\right)$ was performed by first separating the time series in partitions of 16 elements. From each partition five velocities $v_{s_{i}}(i=1,2, \ldots, 5)$ are calculated by a method resembling block averaging, but for non-integer block size. It 

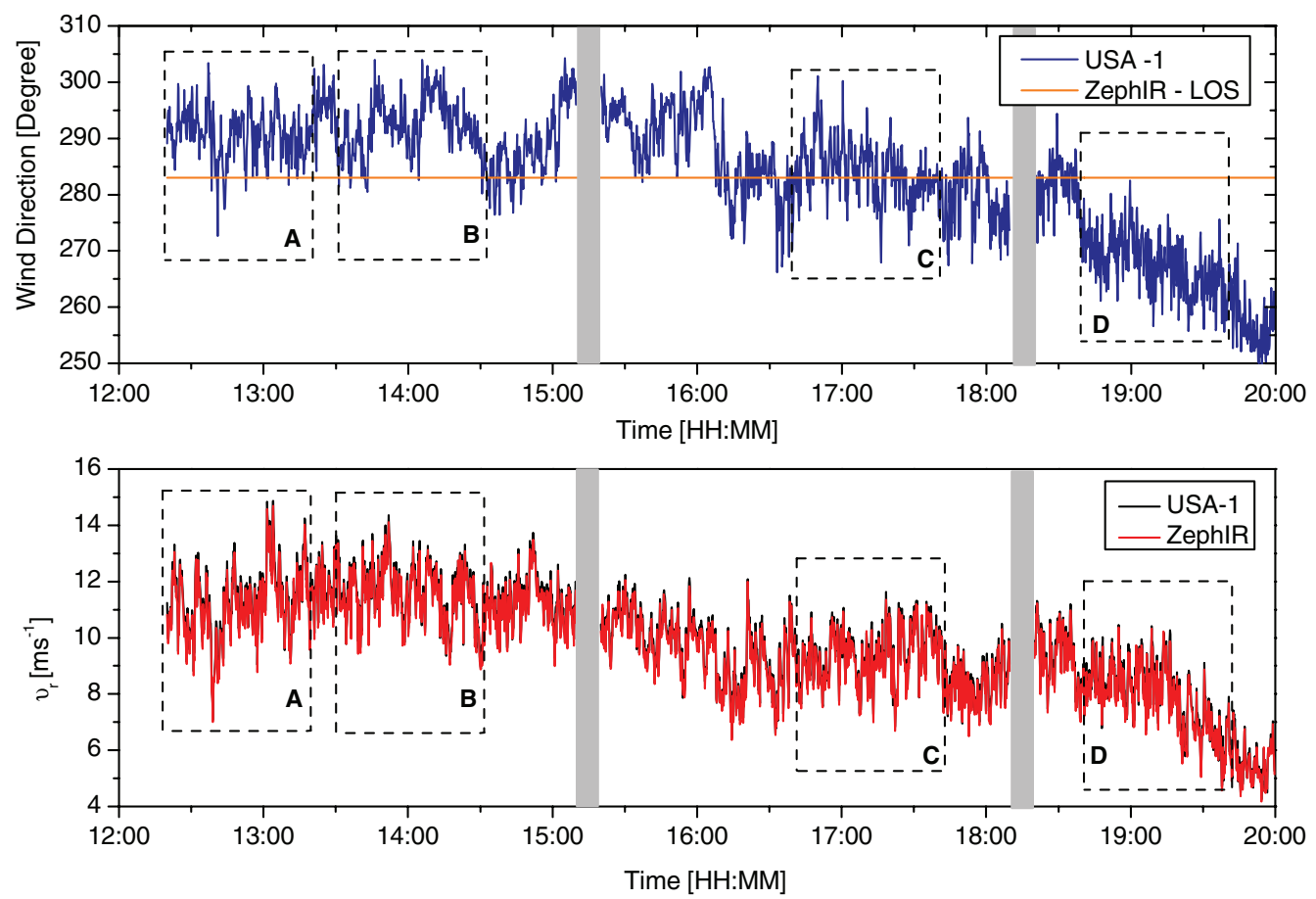

FIG. 1. Time series $(0.1 \mathrm{~Hz})$ of the direction (upper) and radial wind speed (lower) for the period of investigation (12:00-20:00, 05-05-2009).

uses the following discrete weighting function $w_{i}$ :

$$
w_{i}=\{0.2(6-i), 1,1,0.2 i\},
$$

where

$$
\sum_{n=1}^{4} w_{i_{n}}=3.2
$$

so as

$$
v_{s_{i}}=\frac{\sum_{n=1}^{4} w_{i_{n}} v_{n+3(i-1)}}{\sum_{n=1}^{4} w_{i_{n}}}, i=1,2, \ldots, 5 .
$$

As an example of the $10 \mathrm{~Hz}$ time series of the radial wind speed, a sample acquired during the period 17:00-17:08, is presented in Fig. 2. where it can be observed that the laser anemometer is following the wind speed fluctuations detected

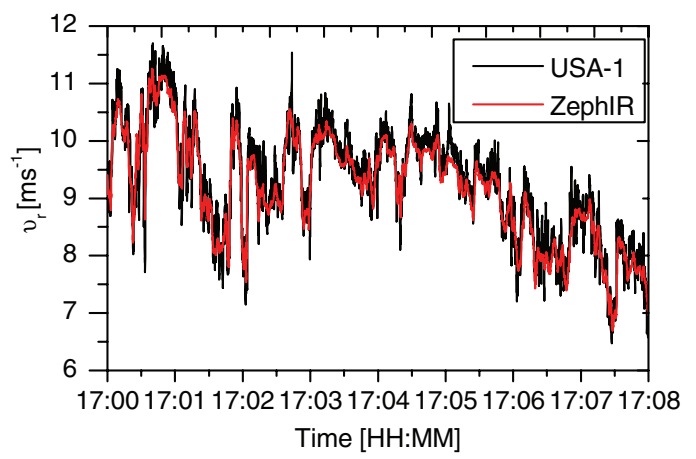

FIG. 2. Time series $(10 \mathrm{~Hz})$ of the radial wind speed acquired between 17:00 and 17:08. by the sonic anemometer, but with a clear attenuation of the small scale turbulence.

\section{RESULTS}

The aim of the analysis was to investigate the observed turbulence attenuation at the high frequencies induced by the sampling volume of the laser anemometer, which is anticipated to behave as a low-pass filter.

\section{A. Spectral analysis}

Figure 3 presents the frequency dependent power spectral density of the wind speed time series, for each of the periods indicated in Fig. 1. The spectra were achieved by first calculating the absolute square of the Fourier Transform of the wind speed time series, subsequently logarithmically smoothed and finally multiplied by the frequency. The frequency band ranges from $1.67 \mathrm{mHz}$ to $5 \mathrm{~Hz}$, corresponding to fluctuations with periods between $10 \mathrm{~min}$ and $200 \mathrm{~ms}$. The analysis was performed using the $10 \mathrm{~Hz}$ block averaged values of the wind speed, for both the measurements of the laser and the sonic anemometers. In order to reduce the uncertainties in the power spectral density the investigated 1-h time periods were divided into 10-min intervals and the spectral results of each of them were subsequently averaged.

It is evident that the highest contribution to the variance of the wind is found in the lower frequency range (cycles with approximately 10-min periods). The spectra derived from the laser anemometer radial wind speed measurements $\left(S_{v_{r}}(f)\right)$ are in all the cases following the corresponding spectra from the sonic $\left(S_{v_{s}}(f)\right)$ up to frequencies of approximately 


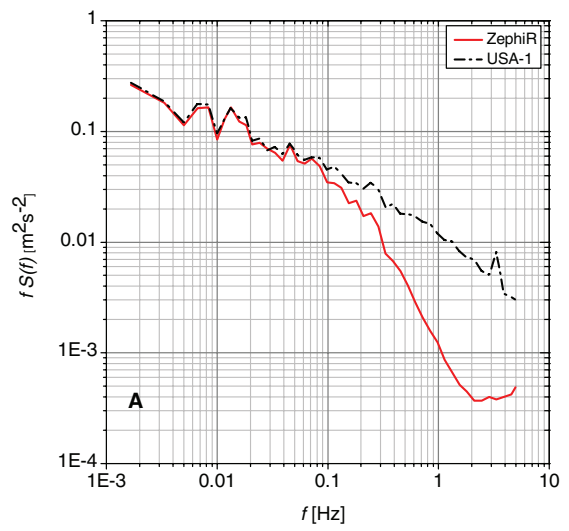

(a) wind direction: $290.5^{\circ}$ LOS deviation: $7.5^{\circ}$

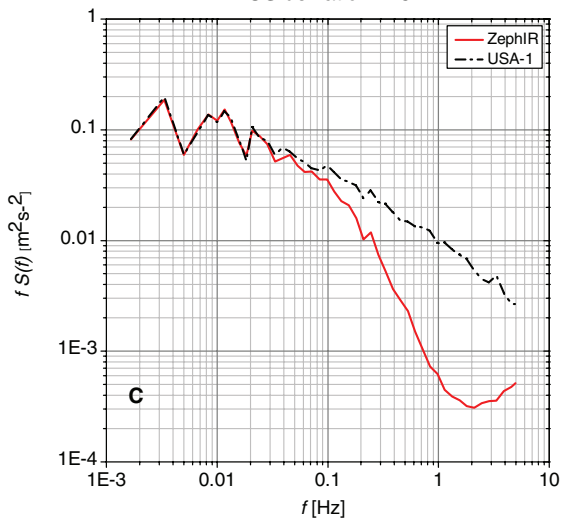

(c) wind direction: $267.6^{\circ}$ LOS deviation: $1.2^{\circ}$

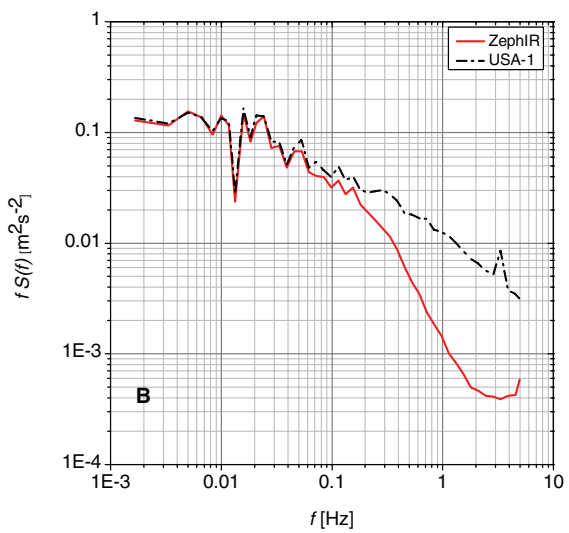

(b) wind direction: $292.4^{\circ}$ LOS deviation: 9.2

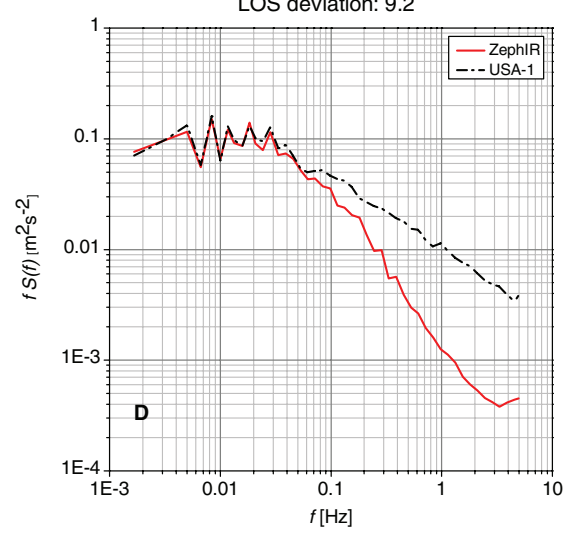

(d) wind direction: $267.6^{\circ}$ LOS deviation: $15.4^{\circ}$

FIG. 3. Spectra of the time series of the wind speed as measured by the ZephIR laser anemometer (red) and by the USA-1 sonic anemometer (dashed black) on the 05-05-2009.

$0.03 \mathrm{~Hz}$. Above that frequency and until almost $2 \mathrm{~Hz}$, the laser anemometer spectra decrease more abruptly than the sonic spectra. This trend can be attributed to the spatial weighting effect which occurs over the probe volume that characterizes the cw laser anemometer measurements. However, above $2 \mathrm{~Hz}$ an increase of the amplitude is observed, probably due to white noise introduced in the laser Doppler spectra.

\section{B. Spectral transfer function}

The spectral transfer function, which represents the turbulence attenuation, that is observed between the measurements of the two sensors, was approached through two different methods using: (a) the power spectral density (method 1) and (b) the cross-spectrum of the sonic anemometer and laser anemometer wind speed measurements (method 2). In both cases the assumption is made that the spatially weighted averaging of the laser anemometer measurements is occurring over exactly the same turbulent fluctuations of the wind speed which are detected by the sonic anemometer, by assuming Taylor's frozen turbulence hypothesis to be valid. ${ }^{16}$

\section{Method 1: Spectral ratio}

The ratio between the wind speed power spectra measured by the two sensors is equal to the absolute square of the
Fourier transform of the spatial weighting function $|\hat{\varphi}(k)|^{2}$, because by Fourier transforming Eq. (2) and assuming Taylor's hypothesis to relate the frequency to the wavenumber $k=\frac{2 \pi f}{v}$,

$$
\begin{aligned}
F_{v_{r}}(k) & =\left\langle\left|\hat{v}_{r}(k)\right|^{2}\right\rangle \stackrel{E q .(2)}{=}\left\langle\left|\hat{\varphi}_{s}(k) \hat{v}_{s}(k)\right|^{2}\right\rangle= \\
& =\left|\hat{\varphi}_{s}(k)\right|^{2}\left\langle\left|\hat{v}_{s}(k)\right|^{2}\right\rangle=\left|\hat{\varphi}_{s}(k)\right|^{2} F_{v_{s}}(k),
\end{aligned}
$$

where $F$ is used for the power spectral density as a function of $k$ and $S$ when a function of $f$. Using the approximate spatial weighting function in the form of the Lorentzian function, Eq. (4), the square of the Fourier transformation $|\hat{\varphi}(k)|^{2}$ is equal with the following exponential:

$$
|\hat{\varphi}(k)|^{2}=e^{-2|k| z_{R}} .
$$

Figure 4 presents the spectral transfer function for each of the time periods. It can be observed that for wavenumbers approximately below $0.02 \mathrm{~m}^{-1}$, the laser anemometer is following the turbulence fluctuations obtained from the sonic anemometer relatively well, with spectral transfer function values between 0.9 and 1.0. Moreover, it is observed that for wavenumbers between 0.1 and $1 \mathrm{~m}^{-1}$ the apparent attenuation decreases as the wind direction deviates more from the lineof-sight of the laser anemometer. The largest attenuation is observed at wavenumbers of about $0.8 \mathrm{~m}^{-1}$, where the spectral density of the detected turbulence fluctuations of the wind 


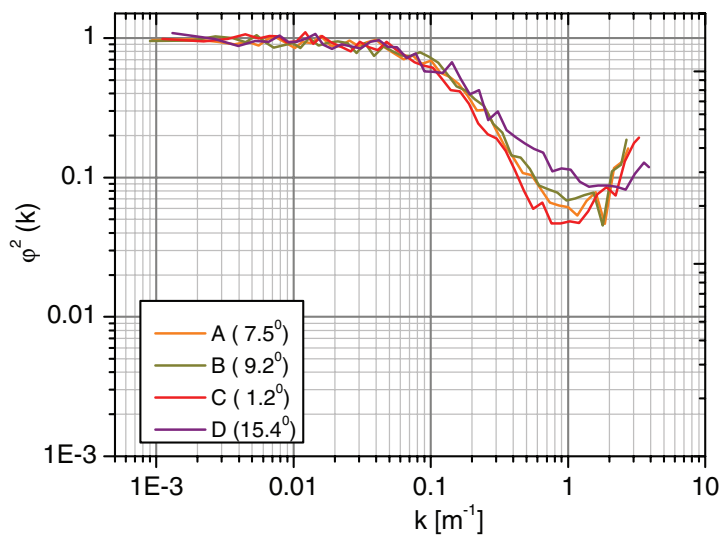

FIG. 4. Ratio between the spectra of the turbulence fluctuations of the wind speed, measured by the ZephIR laser anemometer and the USA-1 sonic anemometer.

speed is only $4 \%$ of the actual. At higher wavenumbers the signals are dominated by noise, which lifts the spectral transfer curve.

\section{Method 2: Cross-spectrum}

An alternative approach for the calculation of the spectral transfer function $\hat{\varphi}(k)$ is through the cross-spectrum $\chi_{v_{r} v_{s}}$ of the laser anemometer and the sonic anemometer wind speed measurements. The cross-spectrum of two signals is defined, ignoring details about the normalization, as the average of the Fourier transform of one of the signals with the conjugated Fourier transform of the other signal:

$$
\begin{aligned}
\chi_{v_{r} v_{s}}(k) & =\left\langle\hat{v}_{r}(k) \hat{v}_{s}^{*}(k)\right\rangle^{E q .(2)}\left\langle\hat{\varphi}(k) \hat{v}_{s}(k) \hat{v}_{s}^{*}(k)\right\rangle \\
\Rightarrow \chi_{v_{r} v_{s}}(k) & =\hat{\varphi}(k) F_{v_{s}}(k) .
\end{aligned}
$$

Assuming the spectral transfer function to be real and by squaring the Eq. (10), an alternative method to calculate the spectral transfer function is obtained:

$$
\begin{array}{r}
\operatorname{Re}\left(\chi_{v_{r} v_{s}}(k)\right)^{2}=\hat{\varphi}^{2}(k) \cdot F_{v_{s}}^{2}(k) \\
\Rightarrow \hat{\varphi}^{2}(k)=\frac{\operatorname{Re}\left(\chi_{v_{r} v_{s}}(k)\right)^{2}}{F_{v_{s}}^{2}(k)} .
\end{array}
$$

The spectral transfer function, calculated using Eq. (11) presents a similar trend with the one of method 1, with the filtering starting to be significant above $0.02 \mathrm{~m}^{-1}$ and an attenuation of $50 \%$ at approximately $0.1 \mathrm{~m}^{-1}$. In Fig. 5 it is seen that the increasing spectral transfer function values, which appeared at high wavenumbers in Fig. 4 can no longer be observed, allowing the turbulence attenuation at high wavenumbers to be distinguished. For instance at a wavenumber of $0.5 \mathrm{~m}^{-1}$ the measured turbulent fluctuations are attenuated to only $0.1 \%$ of their real magnitude.

\section{E. Theoretical spectral transfer function}

The spectral transfer functions derived from Eqs. (8) and (11) were compared with the theoretical

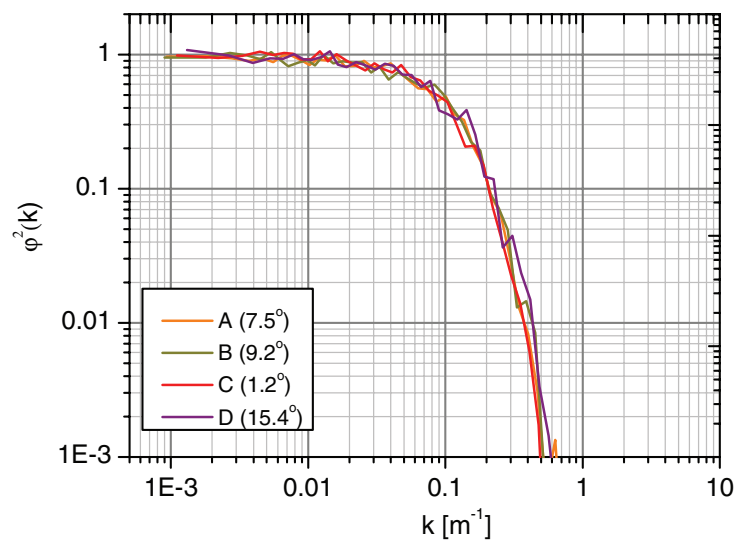

FIG. 5. Square of the ratio between the real part of the cross-spectrum $\chi_{v_{r}} v_{s}$ and the sonic spectrum $F_{v_{s}}$.

expected attenuation, described by Eq. (9) (for $r=67.5 \mathrm{~m}$ and $z_{R}=5.61 \mathrm{~m}$ ), in the case where the minimum deviation between the laser anemometer's line-of-sight and the wind direction is observed, i.e., $1.2^{\circ}$ in period C (see Fig. 6).

Using the approach of method 1 , the measured spectral ratio is following the square of the Fourier transform of the spatial weighting function below wavenumbers of about $0.01 \mathrm{~m}^{-1}$. However, above that value the spectral ratio is not decreasing as fast as the theoretical model predicts. Moreover, above wavenumbers of $1 \mathrm{~m}^{-1}$ an increase is observed in the spectral transfer function which corresponds with the increase which is observed in the laser anemometer spectra in Fig. 3.

Using the second approach (method 2), the spectral transfer function closely follows the theoretical model. Partly this can be attributed to the fact that the uncorrelated noise that is present in the time series of the wind speed measurements of the two sensors is filtered away when calculating the crossspectrum. The values of the spectral transfer function calculated by method 2, are perfectly following the model until $0.5 \mathrm{~m}^{-1}$ where the turbulence attenuation has dropped to approximately $0.1 \%\left(10^{-3}\right)$ of the actual power spectral density.

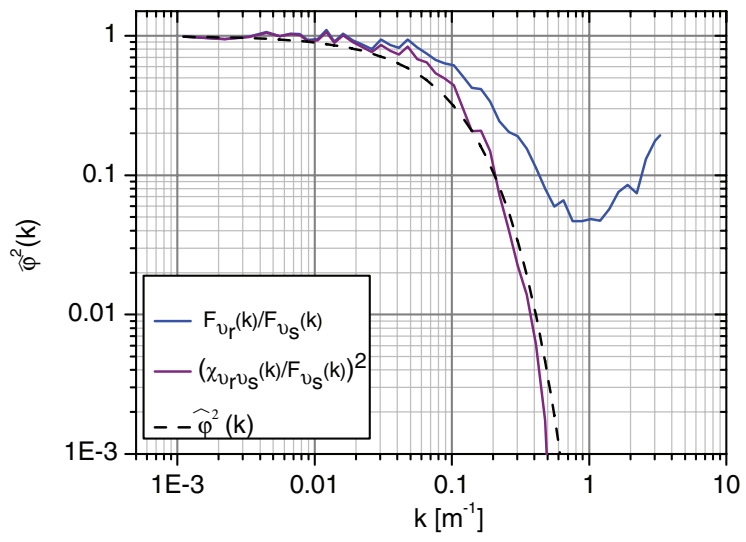

FIG. 6. Comparison of the two methods for estimating the spectral transfer function with the theoretical model of Eq. (9), for data of the period C. 


\section{POSSIBLE REASONS FOR THE DIFFERENCES BETWEEN THE METHODS}

\section{A. Wind direction variations}

Despite the fact that in theory method 1 (Eq. (8)) and method 2 (Eq. (11)) should approach the same spectral transfer function, in Fig. 6 large deviations between the two methods are appearing, especially above wavenumbers of $0.1 \mathrm{~m}^{-1}$. One reason could be that the mean wind vector is not perfectly aligned with the laser beam.

In order to assess the effect of a possible misalignment it is necessary to calculate theoretically the sonic spectrum $F_{v_{s}}(k)$ of the wind velocity component along the line-ofsight of the laser beam determined by the unit vector $\boldsymbol{n}$, the laser anemometer spectrum $F_{v_{r}}(k)$, and the cross-spectrum between the laser anemometer and sonic signals $\chi_{v_{r} v_{s}}$. As in Refs. 12 and 17 these quantities can be expressed in terms of the spectral velocity tensor $\Phi_{i j}$ which is a function of the three-dimensional wave-vector $\boldsymbol{k}=\left(k_{1}, k_{2}, k_{3}\right)$. The expressions are, assuming Taylor's hypothesis,

$$
\begin{gathered}
F_{v_{s}}\left(k_{1}\right)=n_{i} n_{j} \int_{-\infty}^{\infty} \int_{-\infty}^{\infty} \Phi_{i j}(\boldsymbol{k}) d k_{2} d k_{3}, \\
F_{v_{r}}(k)=n_{i} n_{j} \int_{-\infty}^{\infty} \int_{-\infty}^{\infty} \Phi_{i j}(\boldsymbol{k}) \exp \left(-2 z_{R} \boldsymbol{k} \cdot \boldsymbol{n}\right) d k_{2} d k_{3},
\end{gathered}
$$

and

$$
\chi_{v_{r} v_{s}}=n_{i} n_{j} \int_{-\infty}^{\infty} \int_{-\infty}^{\infty} \Phi_{i j}(\boldsymbol{k}) \exp \left(-z_{R} \boldsymbol{k} \cdot \boldsymbol{n}\right) d k_{2} d k_{3} .
$$

When the beam is aligned with the mean wind, i.e., $\boldsymbol{n}=(1,0,0)$, then $F_{v_{r}}(k) / F_{v_{s}}(k)=\left(\chi_{v_{r} v_{s}}(k) / F_{v_{s}}(k)\right)^{2}$ $=\exp \left(-2|k| z_{R}\right)$ in accordance with Eqs. (8) and (11). However, when $\boldsymbol{n}=(\cos (\theta), \sin (\theta), 0)$ with $\theta \neq 0$ that simple relationship no longer holds. As in Refs. 12 and 17 a spectral tensor model ${ }^{18}$ was fitted to the measured sonic spectra and three parameters describing the tensor were obtained. Examples with spectral tensor parameters obtained from Period $\mathrm{C}$ are shown in Fig. 7. It is seen that for non-zero $\theta$ (e.g., $\left.\theta=5^{\circ}\right)$ the ratios are larger than $\exp \left(-2|k| z_{R}\right)$ and that they

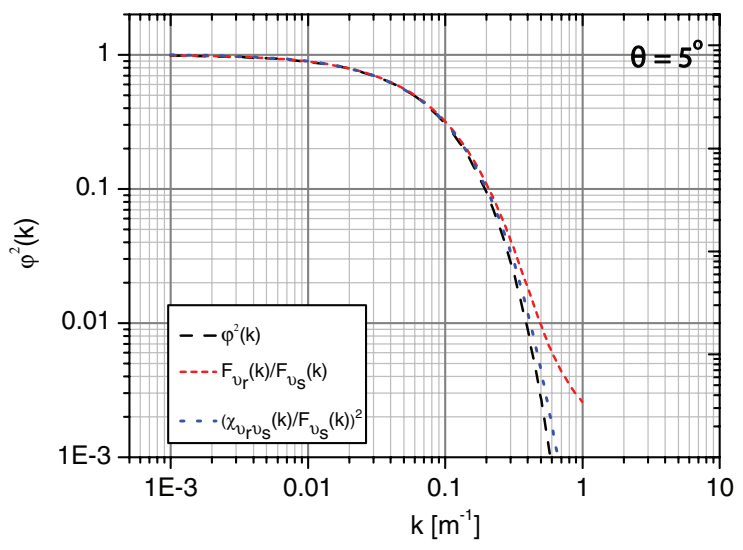

FIG. 7. Spectral ratios calculated from Eqs. (12) to (14) using spectral tensor parameters from period $\mathrm{C}$ for a misalignment angle $\theta=5^{\circ}$.

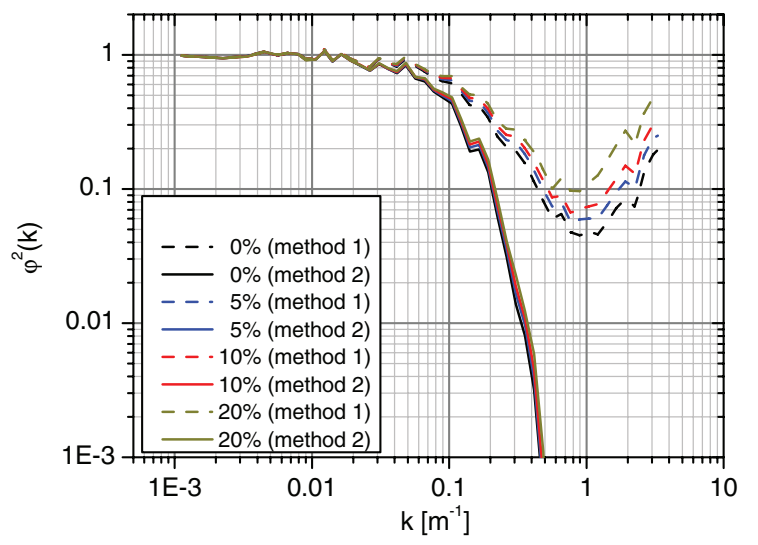

FIG. 8. Spectral transfer function calculated for various threshold levels of the laser's Doppler spectra for data of the period C.

differ such that $F_{v_{r}} / F_{v_{s}}>\chi_{v_{r} v_{s}}^{2} / F_{v_{s}}^{2}$ which can also be seen in the data in Fig. 6. However, for period $\mathrm{C}$ the misalignment is very small indeed, but it could be argued that this small average angle is composed of larger misalignment angles with differing signs over shorter periods, see Fig. 1. This does not explain the difference of $F_{v_{r}} / F_{v_{s}}$ and $\chi_{v_{r} v_{s}}^{2} / F_{v_{s}}^{2}$ quantitatively, but shows that such differences are indeed possible theoretically.

\section{B. Doppler spectra threshold}

The differences between the two methods in the spectral transfer function for wavenumbers above $0.05 \mathrm{~m}^{-1}$ could possible also be attributed to overestimating the laser background output. The laser Doppler spectra contain background noise which should be filtered out prior to post-processing analysis, through which the representative Doppler frequency of the detected wind speed is estimated. ${ }^{19}$

In this experiment only the thresholded spectra were stored, therefore in order to investigate the effect of thresholding of the laser Doppler spectra, an increased threshold was applied equal to $5 \%, 10 \%$, and $20 \%$ of the original value of each spectra. Subsequently the spectral analysis of method 1 and 2 was followed in order to estimate the spectral transfer function. Figure 8 presents the results, where it can be observed that the increase of the threshold is affecting the spectral transfer function calculated using the method 1 , by reducing the estimated turbulence attenuation in the wavenumber range above $0.05 \mathrm{~m}^{-1}$. In contrast, the spectral transfer function of the second method does not show the same increase, which can be explained by the fact that the introduced noise in the laser anemometer measurement is independent from the noise of the sonic anemometer measurements and therefore it is filtered out during the calculation of the cross-spectrum.

\section{CONCLUSIONS}

In this paper the spectral characteristics of the wind speed fluctuations as measured by a ZephIR prototype laser anemometer in comparison to a USA-1 Metek sonic anemometer were studied. In particular, the effect of the laser anemometer's probe volume on the turbulence measurements 
was investigated. Two different methods were followed and compared for the estimation of the spectral transfer function.

The theoretical model for the attenuation of the frequency dependent amplitude of the wind speed fluctuations was well approached, using the cross-spectrum between the USA-1 sonic anemometer and the ZephIR laser anemometer. It was observed that the detection of the turbulent fluctuations of the wind speed from the ZephIR prototype laser anemometer is falling to $50 \%$ in comparison with a sonic anemometer, for wavenumbers approximately between 0.1 and $0.2 \mathrm{~m}^{-1}$.

In contrast, when the spectral transfer function was determined from the ratio of the spectra, higher values than the ones derived from the model were observed. The differences observed are mainly due to the fact that uncorrected measurement noise in the laser anemometer and sonic anemometer is effectively suppressed in the cross-spectra while it makes a large contribution to the individual auto-spectra.

The spectral analysis indicates that the deviation between the two methods can be partially attributed to an overestimation of the background noise floor in the laser Doppler spectra. Which can be explained by the fact that the Doppler shift frequency estimator method used in this study, based on the location of the median value of the Doppler spectrum, is sensitive to high frequency fluctuations of the wind speed. A minor part of the differences could also be attributed to the wind direction fluctuations around the line-of-sight of the laser anemometer, as found in the theoretical study. However neither of the above explanations could fully account for the observed differences between the two methods used for obtaining the laser anemometer's spectral transfer function.

\section{ACKNOWLEDGMENTS}

The authors would like to gratefully acknowledge Per Hansen, René Kjærsgaard, and Michael Rasmussen for their technical support and Professor Torben Mikkelsen for his constructive comments on this paper. The experiment has been conducted as a part of the Work Package 6 of the Upwind project, which is part of the European Unions Sixth Framework Program (FP6). The work was partially supported by the Center for Computational Wind Turbine Aerodynamics and Atmospheric Turbulence under the Danish council for strategic research, Grant No. 09-067216.

${ }^{1}$ T. Fyjii, and T. Fukuchi, Laser Remote Sensing (Taylor \& Francis, Boca Raton, 2005).

${ }^{2}$ S. Emeis, M. Harris, and R. M. Banta, Meteorol. Z. 16, 337 (2007).

${ }^{3}$ C. J. Karlsson, F. A. A. Olsson, D. Letalick, and M. Harris, Appl. Opt. 39(21), 3716 (2000).

${ }^{4} \mathrm{M}$. Courtney, R. Wagner, and P. Lindelöw, 14th International Symposium for the Advancement of Boundary Layer Remote Sensing, IOP Conference Series: Earth and Environmental Science Vol. 1 (Curran Associates, 2010).

${ }^{5}$ T. Mikkelsen, EWEC, Poster Session: Wind profiles at great heights PO 171, (2009).

${ }^{6}$ D. A. Smith, M. Harris, S. Coffey, T. Mikkelsen, H. E. Jørgensen, J. Mann, and R. Danielian, Wind Energy 9, 87 (2006).

${ }^{7}$ C. Werner, F. Klöpp, and R. L. Schwiesow, Appl. Opt. 23(15), 2482 (1984).

${ }^{8}$ A. E. Siegman, Lasers (University Science Books, Sausalito, 1986).

${ }^{9}$ C. M. Sonnenschein and F. A. Horrigan, Appl. Opt. 10, 1600 (1971).

${ }^{10}$ T. R. Lawrence, D. J. Wilson, and C. E. Craven, Rev. Sci. Instrum. 43(3), 512 (1972).

${ }^{11}$ I. N. Smalikho, Atmos. Oceanic Opt. 8, 788 (1995).

${ }^{12}$ M. Sjöholm, T. Mikkelsen, J. Mann, K. Enevoldsen, and M. Courtney, Meteorol. Z. 18, 281 (2009).

${ }^{13}$ N. Angelou, J. Mann, M. Courtney, and M. Sjöholm, Risø DTU, Risø-R-1757(EN), 2010

${ }^{14}$ E. Dellwik, J. Mann, and K. S. Larsen, Biogeosciences 7, 1745 (2010).

${ }^{15}$ A. Bechmann, J. Berg, M. S. Courtney, H. E. Jørgensen, J. Mann, and N. N. Sørensen, Risø DTU, Ris $\varnothing-R-1658(E N), 2009$.

${ }^{16}$ G. I. Taylor, Philos. Trans. R. Soc. London 164, 476 (1938).

${ }^{17}$ J. Mann, J. P. Cariou,, M. Courtney, R. Parmentier, T. Mikkelsen, R. Wagner, P. Lindelöw, M. Sjöholm, and K. Enevoldsen, Meteorol. Z. 18(2), 135 (2009).

${ }^{18}$ J. Mann, Prob. Eng. Mech. 13(4), 269 (1998).

${ }^{19}$ F. Bingöl, M. S. thesis, Technical University of Denmark, 2005. 